\title{
Can Retaining Asperger Syndrome in DSM V Help Establish Neurobiological Endophenotypes?
}

\author{
Ahmad Ghanizadeh
}

Published online: 1 May 2010

(C) Springer Science+Business Media, LLC 2010

I studied with interest the article entitled as: "Brief Report: Should the DSM V Drop Asperger Syndrome?" (Ghaziuddin 2010). The core symptoms and possible proposed changes for improving Asperger syndrome definition were discussed and he recommended that Asperger syndrome be retained in the DSM V.

Endophenotypes may help us to find association of behavioral manifestations and basic neurosciences etiology of diagnoses. Autism endophenotypes have also been suggested (Rommelse et al. 2009; Saresella et al. 2009). Endophenotypes of language impairment may offer promising approaches for further genetic and neurobiological studies (Geschwind 2009). This may be particularly relevant for the study of neural mechanisms that mediate genetic risk and clinical features.

Interest in possible PDD subtypes has increased in recent years. Our knowledge of connections to underlying genetic and neural mechanisms remains limited. For example, the issue of co-morbid ADHD and Autism diagnosis is of interest (Sinzig et al. 2009) particularly given the recent report of shared heritability for ADHD and PDDs (Rommelse et al.). Deliniation of possible endophenotypes may help us to know if it is possible that there is a common etiological factor.

\section{References}

Geschwind, D. H. (2009). Advances in autism. Annual Review of Medicine, 60, 367-380.

Ghaziuddin, M. (2010). Brief report: Should the DSM V drop asperger syndrome? Journal of Autism and Developmental Disorders. [Epub ahead of print].

Rommelse, N. N., Altink, M. E., Fliers, E. A., Martin, N. C., Buschgens, C. J., Hartman, C. A., et al. (2009). Comorbid problems in ADHD: Degree of association, shared endophenotypes, and formation of distinct subtypes. Implications for a future DSM. Journal of Abnormal Child Psychology, 37(6), 793804.

Rommelse, N. N., Franke, B., Geurts, H. M., Hartman, C. A., \& Buitelaar, J. K. (2010). Shared heritability of attention-deficit/ hyperactivity disorder and autism spectrum disorder. European Child \& Adolescent Psychiatry, 19(3), 281-295.

Saresella, M., Marventano, I., Guerini, F. R., Mancuso, R., Ceresa, L., Zanzottera, M., et al. (2009). An autistic endophenotype results in complex immune dysfunction in healthy siblings of autistic children. Biological Psychiatry, 66(10), 978-984.

Sinzig, J., Walter, D., \& Doepfner, M. (2009). Attention deficit/ hyperactivity disorder in children and adolescents with autism spectrum disorder: Symptom or syndrome? Journal of Attention Disorders, 13(2), 117-126.

\footnotetext{
A. Ghanizadeh $(\bowtie)$

Shiraz University of Medical Sciences, Research Center for

Psychiatry and Behavioral Sciences, Shiraz, Iran

e-mail: ghanizad@sina.tums.ac.ir
} 